\title{
It's still the media. How professionalism in corporate communication influences the prioritisation of organizational environments
}

\author{
Jochen Hoffmann, Aalborg University, Department of Culture \& Global Studies* \\ Ulrike Röttger, University of Muenster, Department of Communication \\ Rada Babic, University of Salzburg, Department of Communication Science \\ ${ }^{*}$ Corresponding author: hoffmann@cgs.aau.dk
}

\begin{abstract}
This article challenges the widely accepted understanding that corporate communication has been professionalised through its development from traditional press relations into integrated multi-stakeholder management. Based on a cross-cultural survey in Austria, Germany, Switzerland, Australia and Indonesia, we analyse the links between expertise, autonomy and value-orientation indicating the professionalism of senior communication managers on the one hand, and the perceived relevance of organizational environments on the other. Overall, the results show that professionalism in a traditional sense does not promote a wider perspective when dealing with organizational environments. Instead, the more professional practitioners are, the more they focus on the media.
\end{abstract}

\section{Keywords}

corporate communication, professionalism, stakeholder management, integrated communication, media relations

\section{Introduction}

Business environments are complex and organizations are "increasingly called on to establish and maintain trust ties between organizations and a multitude of shifting stakeholders" (Gilpin \& Murphy, 2010, p. 72; see also Slabbert \& Barker, 2014). This widely accepted understanding of corporate communication (CC) is both a challenge for the organization as a whole and a unique task assigned to communication departments (Gregory, 2011). As a result, the professional communication of organizations appears to be developing into an integrated multi-stakeholder form of management, leaving behind restrained concepts of public relations - such as press relations (Bernstein, 1984; Argentini, 2009; Cornelissen, 2014).

But is this assertion really theoretically sound and backed by empirical evidence? The normative idea of professional corporate communication is often a priori equalised with concepts of multi-stakeholder-management. The latter is used to define the former. Instead, we treat professional communication and multi-stakeholder management as two distinct descriptive concepts resulting in separate variables, which may, but do not have to, correlate. The aim of this article is to empirically test an assumption that is often taken for granted: The more professionalised corporate communication practitioners are, the more they are committed to stakeholder management that aims to balance a multitude of societal claims in respect of the organization. Instead of taking over or rejecting this claim on theoretical grounds, we leave the answer to an empirical analysis. The data of our study is derived from a survey of senior communication managers at the biggest corporations in five countries.

\section{Theoretical background and literature review}

Despite the fact that professionalisation claims are widespread in corporate com- 
munication research and teaching, its meaning often remains vague. In many instances, the need to furnish sufficient theoretical reflection was left by the wayside (Faber, 2001). Thus, it is worthwhile tracing the theoretical roots of professionalism before relating the concept to corporate communication practices.

Sociological trait approaches that attempt to describe and explain professionalism were developed primarily in the course of the 1970s (Freidson, 1970; Elliott, 1972; Larson, 1977). They list features distinguishing a profession from an "ordinary" occupation. These lists are often fairly long, but the majority of the items can be reduced to three main dimensions (Hoffmann \& Hamidati, 2016):

Expertise: professions apply an exclusive and specialist body of knowledge that requires a sophisticated (academic) education.

Autonomy: neither politics nor the rules of the market determine how professions operate. Professions are relatively independent from outsides pressures. They are governed by self-regulating associations and professionals play a more senior role within organizations.

Value orientation: professions claim a strong normative orientation toward the common good. Medical practitioners, for instance, claim to cure people, while lawyers claim to contribute to greater justice in society. Professional work is about more than 'creating value' for the company or distinct stakeholders; instead, it is a commitment to the values of society as a whole.

The interpretation of these dimensions depends on the underlying paradigm. As in many other academic discourses, we can distinguish between a functionalist and a critical perspective (Evetts, 2008; Hoffmann \& Hamidati, 2016). Functionalists employ a positive stance toward professionalism. They argue that professions fulfil indispensable functions for society as a whole. They contribute to the realisation of distinct societal values (like health or justice) by applying their skills in a re- sponsible way. This justifies their autonomy and superior role within organizations and within society (Parsons, 1968).

From a critical perspective, autonomy means power. Therefore, the ultimate goal of a profession is less the realisation of societal values; it is more the minimisation of external interventions into the professional field and vice versa to gain as much control as possible over practices. Thus, the value orientation of professionals is merely a kind of front-stage presentation. Their exclusive expertise is used to monopolise a field of activity: ultimately, they are self-interested societal players who are very much driven by commercial and political motives (Freidson, 1994).

Since the 1990s, corporate communication scholars worldwide (Cameron, Sallot, \& Weaver-Lariscy, 1996; Kim \& Hon, 1998; Wu \& Taylor, 2003; Lim, Goh, \& Sriramesh, 2005; Kirat, 2006; Gupta, 2007; Niemann-Struweg \& Meintjes, 2008; Zulhamri \& Threadgold, 2008; Sriramesh \& Verčič, 2009; Mellado \& Barria, 2012) have taken up certain aspects of the sociological trait approach. Usually, they are inspired by the functionalist "PR excellence" research tradition (Grunig, Grunig, \& Dozier, 2002) where professionalism and excellence appear to be more or less synonymous. While the authors sketch dynamic developments, most conclude what Wyllie (1994) stated more than 20 years ago: "Public relations is not yet a profession." One is tempted to add: at least not outside the United States. Critical scholars (Pieczka, 2000; Pieczka \& L'Etang, 2001; Holtzhausen, Petersen, \& Tinsall, 2003; Pal \& Dutta, 2008) deconstructed the functionalist PR professionalisation and excellence paradigm as an expression of cultural ethnocentrism (see also Hoffmann, 2016; Hoffmann \& Hamidati, 2016).

Surprisingly, both research strands would very much agree on indicators as to how to describe professions, even though this would entail highly contradictory normative implications. In contrast, in the present study we intend to remain on the descriptive level and find out how professionalism relates to a development illustrated by a gradual change of terminology 
toward corporate communications, which is often positioned as "a more contemporary and sophisticated form of public relations" (Christensen \& Cornelissen, 2011, p. 386). Communication scholars took up ideas from stakeholder theories claiming a '360 degree view' on corporate environments (Freeman, Harrison, Wicks, Parmar, \& De Colle, 2010). A media-focussed perspective seems to transform into corporate communication as "an expanding project" (Christensen, Morsing, \& Cheney, 2008, p. 51) that aims "to manage all communications under one banner" (Christensen \& Cornelissen, 2011, p. 386). Christensen, Morsing, and Cheney (2008) challenged this claim due to its implicit consistency ideal, which fails to account for the multivocality of organizations and the tensions resulting from contradicting stakeholder claims.

In spite of these critical voices, the belief in the manageability of 'integrated' stakeholder communication remains to be the underpinning idea of functionalist discourses on professional communication. The assumption that traditional concepts of professionalism are the foundation for appropriate management responses to complex stakeholder expectations has been somewhat taken for granted thus far. We instead position the assumption as an empirical research question and investigate, whether professionalism supports corporate communication in the form of multi-stakeholder management. How does the degree of professionalism with regard to autonomy, expertise and value orientation relate to the idea of corporate communication as an expanding and integrating project? We want to know whether a higher degree of professionalism does indeed go hand in hand with a broad and balanced multi-stakeholder management.

There are only a small number of studies measuring the impact of professionalism on distinct practice areas. $\mathrm{Li}$, Cropp, Sims, and Jin (2012) assume that Chinese communication practitioners focusing on consumer relations perceive a higher degree of autonomy and strategic orientation than their colleagues in media relations. This may be due to the unique- ness of the Chinese media system, which does not leave much room for professional corporate media campaigns. Another two studies explore the link between professionalism and perceptions of corporate social responsibility (CSR). While an earlier study (Wright, 1979) did not find any specific links, Kim and Reber (2009) concluded that, in the United States at least, professionalism in public relations supports CSR. However, their operationalisation of the degree of professionalism and of the CSR dimension is not sensitive towards response biases. Both variables are very much positively loaded. It might well be the case that they in fact measured individual tendencies towards social desirability, thereby inducing a spurious correlation between professionalism and CSR.

Even though there are not yet sufficient empirical answers, the potential broadening and integrating impact of professionalism on CC practices is taken for granted from a functionalist PR perspective: "Public relations professionals (Grunig, Grunig, \& Dozier's emphasis), by definition (our emphasis), believe that their role is to balance the interests of their clients with interests of the publics that constitute society." (Grunig, Grunig, \& Dozier, 2002, p. 328). Our approach is to deconstruct this definition and transform it into an empirical research question: How does the degree of professionalism impact on the perception of corporate environments? Do professionalised corporate communication practitioners contribute to a broad stakeholder management that attempts to balance a multitude of claims towards the organization? Or does a high degree of professionalism correlate with a prioritisation of distinct segments of the organizational environment?

\section{Methods}

The data is derived from an international survey on corporate communication cultures that allows us to test our hypothesis on a global scale. We identify links between professionalism in corporate communication and the perception of the or- 
ganizational environment, which are not only a reflection of a distinct cultural and institutional context. The survey method allows us to focus on the perceptions of the practitioners themselves, not only regarding the salience of communication practices, but also when it comes to the corporate context of their work. The problem of many 'country reports' in the field is that secondary context data are used to describe an 'objectified' and deterministic corporate environment on the macro-level of society, without accounting for interpretations of those who are exposed to these contexts. After all, it is the practitioners' views which matters and their perceptions can be reconstructed e.g. through primary survey data.

\subsection{Data collection}

The research was designed as an umbrella project that provided a rich database for a number of topics (Hoffmann, Röttger, Ingenhoff, \& Hamidati, 2015; Hoffmann, 2016; Hoffmann \& Hamidati, 2016). A comprehensive online survey was distributed in five countries which, according to the cross-cultural GLOBE study (House, Hanges, Javidan, Dorfman, \& Gupta, 2004; Chhokar, Brodbeck, \& House, 2008), can be assigned to three cultural clusters: Austria, Germany, and Switzerland, representing a "Germanic Europe" cluster; Australia, representing an "Anglo" cluster; and Indonesia, representing a "Southern Asian" cluster. We took efforts to include more countries from Asia in particular, but finding reliable cooperation partners turned out to be impossible in some cases.

Another methodological challenge was to access the field in all included countries according to the same criteria. Access via membership directories of 'professional' associations produces a sample bias (Hazleton \& Sha, 2012), particularly when professionalism is at the heart of the analysis. Moreover, there are no associations in which a majority of communication practitioners are members. The popular "snowball technique" (e.g. de Bussy \& Wolf, 2009; Li, Cropp, Sims, \& Jin, 2012) does not provide a systematic, transparent and controlled access either. Consequent- ly, we decided to access the field via organizations. The bigger an organization is in terms of turnover, the higher the probability that somebody is in charge of its communication (Röttger, Hoffmann, \& Jarren, 2003). Therefore, we defined our sample as the practitioners who occupy the most senior positions in corporate communication in the companies with the highest turnover (total revenue) in the five selected countries. We decided to use the Orbis database, which is the most comprehensive global database and lists the companies with the highest turnover in predetermined countries.

The next challenge was to obtain an acceptable response rate. There is a global cross-disciplinary trend of decreasing response rates, and public relations has not been spared from this trend (e.g., Huang, 2012). With this in mind, we decided to invest project resources primarily into efforts to contact practitioners in a way that ensured that they were most likely to respond. Each potential respondent was sent an invitation by email or fax. However, to ensure success, the project team went further by calling up to 800 companies in each country and attempting to build ties with the relevant head of corporate communication in order to extend a personal invitation. This contact strategy was time-consuming, but successful. Our adjusted, cleansed sample comprised 2530 companies, with an overall response rate of $16.5 \%$. This rate was lowest in Austria at $12.4 \%$ and highest in Switzerland at $25.4 \%$. The analysed sample included 418 questionnaires.

\subsection{Data analysis}

The key idea behind our research design is to strictly distinguish variables indicating the degree of professionalism on the one hand, from variables indicating the perceived relevance of organizational environments on the other. This is the only form of design that allows to find out whether or not there is a positive correlation between professionalism and multi-stakeholder management. The commitment to the latter was operationalised using two item sets. Instead of con- 
fronting the respondents with long lists of over-differentiated scales, they dragged and dropped 14 areas of corporate communication and 18 groups of stakeholders into three fields according to relevance: most important; of average importance; and least important. This was a quick and convenient way to identify the perceived relevance of each item. In our statistical analysis we reduced the number of items to a few underlying dimensions by applying a factor analysis to the CC areas and stakeholders. Factor analysis is a powerful statistical tool that allows the structure behind potentially ambiguous and overlapping items to be identified. Herein lies its unique strength as an inductive multivariate research method whose purpose is not to apply predetermined theoretical categories, but to derive an underlying structure from the data themselves. Thus, what we get from the factor analysis is a taxonomy comprising factors that show how the respondents categorize practice areas in combination with stakeholder salience.

We applied a principal component analysis with Varimax rotation in order to improve the discriminatory power of each underlying factor. The KMO values were above 0.6 and therefore considered acceptable. We also checked the MSA values for each individual item with the help of the anti-image test. The only item we needed to skip was Internal Communication as a CC area. This does not mean that internal communication is not important - most respondents across all societies rate it highly. As such, the variable itself was not capable of contributing to any differentiation of professional role understandings. We determined the number of extracted factors according to the Kaiser criterion (eigenvalue min. 1), corrected using the scree plot results if necessary. Additionally, the factor values were calculated for each respondent. The factor value is a variable representing the relevance of an identified factor in relation to all other units of analysis. It can range from -1 to +1 . The factor values indicate for each respondent the degree to which they are guided by the perceptional patterns empirically extracted from the factor analysis. Both the stakeholder salience and the perceived relevance of distinct practices feed into these patterns and form our dependent variable, allowing us to find out whether respondents focus or do not focus on distinct segments of the corporate environment. Such a complex measurement of relative differences provides more robust results than simply identifying the absolute tendency of a respondent towards finding a greater or smaller number of practice areas and stakeholders important. The latter is prone to a systematic measurement error caused by social desirability. Rating items high as a matter of course can easily turn into an impression-management exercise aimed at aligning responses with professional expectations.

For the independent variable, we operationalised the three sub-dimensions of professionalism, as discussed above, with a variety of indicators:

Expertise: We questioned the respondents regarding their education and the extent to which they are able to focus on corporate communication in their workload. This indicates the exclusivity and acknowledgement of their unique expertise as communication practitioners within the organization.

Autonomy: We asked about membership in communication associations that aim to ensure professional autonomy e.g. by controlling access to the vocational field (societal level). We also wanted to know whether respondents are head of a separate communication department (organizational level) and how they perceived their own impact on organizational decisions (individual level).

Value orientation: There are a number of values enhanced by ethical codes worldwide. We specifically asked the respondents about their commitment to transparency, since this is a value of special relevance within the communication industry (Fombrun \& Rinova, 2000).

In the following, we first present for each country the frequencies indicating the relevance of the 14 CC areas and 18 stakeholders. We will then use the factor anal- 
ysis to extract underlying perceptional patterns. Next, we analyse the relationship between the factor values on the one hand (which indicate the salience of corporate context perceptions for each respondent), and the degree of professionalisation on the other. We performed correlations (Pearson's $r$ and Spearman's r), frequency comparisons in cross tabulations (significance tests: chi-square) as well as mean comparisons (significance tests: one-way ANOVAs). Ultimately, this will enable us to establish whether 'professional' respondents are committed to multi-stakeholder-management or whether they tend to focus on certain segments of the corporate environment.

\section{The perception of the organiza- tional environment: relevance of corporate communication areas and stakeholders}

Overall, Media Relations is the most important area of corporate communications in all countries (see table 1). Internal Communication is also rated highly with scores of between $67.9 \%$ in Indonesia and $87.8 \%$ in Germany. What is special about Indonesia is that there is a strong focus both on political communication items and on Investor Relations.

Accordingly, Indonesian practitioners focus more than their colleagues in the other countries on Government/Parliament and the Public Administration as political stakeholders, as well as on Stockholders/Investors (see table 2). Competitors also score higher than in the other countries. Overall, Employees, Customers and Print Media are the most important stakeholders. Surprisingly, activists and NGOs rank very low. In the European countries in particular, the focus on mass media and the general public is far greater.

The factor analysis including both the CC areas and the stakeholders reveals four basic role orientations as far as the organizational environment is concerned (Hoffmann, Röttger, Ingenhoff, \& Hamidati, 2015; see table 3):

An orientation towards politics: Government/Parliament, Public Administration, Activists/Non Governmental Organizations, Political Parties as stakeholders, Government Relations/Public Affairs/Lobbying as CC area load high on this factor.

- An orientation towards the media: Print Media, Broadcast Media, Online Media

Table 1: $\quad$ Percentage of most important corporate communication areas (in\%)

\begin{tabular}{|c|c|c|c|c|c|c|}
\hline & Australia & Indonesia & Germany & Austria & $\begin{array}{r}\text { Switzer- } \\
\text { land }\end{array}$ & Sig. $\left(\chi^{2}\right)$ \\
\hline Media Relations & 79.9 & 85.7 & 97.3 & 91.7 & 88.2 & .014 \\
\hline Internal Communication & 77.2 & 67.9 & 87.8 & 85.0 & 81.4 & .015 \\
\hline Crisis Communication & 60.8 & 69.1 & 61.1 & 50.9 & 39.8 & .002 \\
\hline Issues Management & 64.6 & 65.5 & 37.3 & 38.0 & 41.6 & .000 \\
\hline Internet/Social Media Communication & 39.2 & 47.3 & 50.0 & 44.1 & 47.0 & .473 \\
\hline Government Relations/Public Affairs/Lobbying & 48.7 & 63.2 & 37.3 & 26.0 & 36.5 & .000 \\
\hline Investor Relations & 45.2 & 64.9 & 36.5 & 29.2 & 35.7 & .001 \\
\hline Stakeholder Management & 68.0 & 50.9 & 32.8 & 36.5 & 24.0 & .000 \\
\hline Media Production & 17.3 & 25.9 & 27.5 & 33.9 & 34.9 & .059 \\
\hline Event Management & 18.2 & 24.1 & 30.6 & 33.3 & 30.6 & .217 \\
\hline Community Relations & 30.3 & 29.1 & 16.7 & 18.8 & 13.7 & .005 \\
\hline $\begin{array}{l}\text { Media Training/ Briefing/ } \\
\text { Coaching }\end{array}$ & 18.2 & 27.3 & 15.4 & 18.2 & 15.0 & .070 \\
\hline Sponsorship & 14.5 & 9.3 & 6.8 & 22.8 & 13.6 & .033 \\
\hline Fundraising & 1.4 & 7.4 & 0.0 & 0.0 & 3.3 & .001 \\
\hline
\end{tabular}


Table 2: Percentage of most important corporate communication stakeholders (in\%)

\begin{tabular}{lrrrrrr}
\hline & Australia & Indonesia & Germany & Austria & Switzerland & Sig. $\left(\chi^{2}\right)$ \\
\hline Employees & 94.7 & 84.9 & 91.3 & 94.8 & 83.6 & .186 \\
Customers & 85.1 & 92.2 & 79.7 & 91.4 & 80.4 & .365 \\
Print Media & 67.1 & 72.7 & 91.2 & 84.5 & 78.4 & .004 \\
Broadcast Media & 48.7 & 67.3 & 61.5 & 63.0 & 57.8 & .032 \\
Stockholders/ & 54.2 & 85.2 & 47.6 & 40.4 & 49.0 & .000 \\
Investors & 26.7 & 46.4 & 70.6 & 62.1 & 57.3 & .000 \\
General Public & 43.2 & 56.4 & 52.4 & 51.8 & 41.7 & .339 \\
Online Media/ & & & & & & \\
Social Media & 56.2 & 63.0 & 20.0 & 27.5 & 32.7 & .000 \\
Government/ & 33.3 & 34.0 & 21.9 & 41.5 & 25.0 & .225 \\
Parliament & 27.0 & 25.0 & 25.4 & 25.5 & 21.8 & .055 \\
Suppliers & 14.1 & 33.3 & 11.3 & 23.5 & 26.9 & .008 \\
Local Communities & 16.7 & 39.2 & 9.5 & 15.4 & 14.0 & .000 \\
Public Administration & 29.2 & 26.4 & 8.1 & 11.5 & 10.9 & .000 \\
Competitors & 5.5 & 8.0 & 10.8 & 18.9 & 13.1 & .000 \\
Industry Associations & 18.1 & 0.0 & 14.1 & 5.9 & 9.2 & .004 \\
Academia/ Experts & 14.1 & 11.8 & 9.5 & 6.1 & 8.4 & .126 \\
Political Parties & 11.0 & 11.8 & 11.3 & 7.8 & 5.2 & .100 \\
Trade Unions & 1.4 & 17.6 & 1.7 & 4.3 & 0.0 & .000 \\
Activist groups/ & & & & \\
Non Governmental Organizations & & & & \\
Legal Institutions/ Courts & & & & & \\
\hline Note. The iespon
\end{tabular}

Note. The respondents rated each stakeholder either as most important, of average importance or least important. The table indicates the percentage of respondents rating the respective stakeholder as most important, $\mathrm{N}=321-368$.

Table 3: Corporate communication practice factors: Rotated component matrix

\begin{tabular}{|c|c|c|c|c|c|c|c|c|c|}
\hline & \multicolumn{4}{|c|}{ Component } & & \multicolumn{4}{|c|}{ Component } \\
\hline & Politics & Media & Market & Investors & & Politics & Media & Market & Investors \\
\hline \multirow{2}{*}{$\begin{array}{l}\text { Government/ } \\
\text { Parliament }\end{array}$} & \multirow[t]{2}{*}{.786} & \multirow[t]{2}{*}{-.018} & \multirow[t]{2}{*}{-.147} & \multirow[t]{2}{*}{.101} & Media relations & .094 & .603 & -.147 & \multirow{2}{*}{$\begin{array}{r}.094 \\
-.278\end{array}$} \\
\hline & & & & & General public & .188 & .530 & -.121 & \\
\hline \multirow{2}{*}{$\begin{array}{l}\text { Public administration } \\
\text { Competitors }\end{array}$} & .586 & .046 & .047 & -.037 & \multirow{2}{*}{$\begin{array}{l}\text { Internet/Social media } \\
\text { communication }\end{array}$} & \multirow{2}{*}{-.149} & \multirow[t]{2}{*}{.538} & \multirow[t]{2}{*}{.234} & \multirow[t]{2}{*}{-.283} \\
\hline & .080 & -.031 & .572 & .070 & & & & & \\
\hline Employees & .105 & -.045 & .357 & -.069 & Media production & -.252 & .367 & .381 & -.130 \\
\hline Stockholders/Investors & .050 & .001 & .101 & .752 & Investor relations & .034 & .009 & .085 & .802 \\
\hline Print media & -.037 & .786 & -.134 & .056 & Crisis communication & .318 & .470 & -.105 & .233 \\
\hline Broadcast media & .185 & .720 & -.190 & .115 & Sponsorship & .212 & -.009 & .113 & -.435 \\
\hline \multirow{2}{*}{$\begin{array}{l}\text { Online media/ } \\
\text { Social media }\end{array}$} & \multirow[t]{2}{*}{-.086} & \multirow[t]{2}{*}{.709} & \multirow[t]{2}{*}{.079} & \multirow[t]{2}{*}{-.125} & \multirow{3}{*}{$\begin{array}{l}\text { Fundraising } \\
\text { Event management } \\
\text { Issues management }\end{array}$} & \multirow{2}{*}{$\begin{array}{r}.322 \\
-.078\end{array}$} & .001 & .349 & .056 \\
\hline & & & & & & & .036 & .343 & -.375 \\
\hline Suppliers & -.153 & -.198 & .663 & .026 & & .433 & .233 & -.127 & .319 \\
\hline \multirow{2}{*}{$\begin{array}{l}\text { Customers } \\
\text { Academia/Experts }\end{array}$} & -.052 & -.087 & .529 & -.019 & Community relations & .432 & .039 & .168 & -.020 \\
\hline & -.030 & .336 & .442 & -.085 & Stakeholder & .385 & -.175 & .146 & .461 \\
\hline Trade unions & .305 & .142 & .382 & .256 & management & & & & \\
\hline Industry associations & .347 & -.102 & .408 & .144 & Media training/ & .263 & .388 & .242 & .096 \\
\hline Activist groups/ & .527 & .300 & .038 & .033 & Briefing/Coaching & & & & \\
\hline Non- governmental & & & & & Explained variance & $13.9 \%$ & $10.7 \%$ & $8.0 \%$ & $6.4 \%$ \\
\hline organizations & & & & & Eigenvalue & 4.3 & 3.3 & 2.5 & 2.0 \\
\hline Local communities & .454 & .158 & .131 & -.142 & & & & & \\
\hline Political parties & .593 & -.011 & -.119 & -.191 & & & & & tation \\
\hline Legal institutions/ & .450 & .009 & .246 & .174 & & & & & \\
\hline
\end{tabular}


and Social Media, the General Public as stakeholders, Media Relations and Internet/Social Media Communication as $\mathrm{CC}$ areas load high on this factor.

> An orientation towards the market: Competitors, Suppliers and Customers as stakeholders load high on this factor.

- An orientation towards investors: Stockholders/Investors as stakeholders and Investor Relations as CC area load high on this factor.

The results of the factor analysis show how practitioners structure their organizational environment into distinct segments. The question is whether the professionalisation process promotes the prioritisation of one of these segments, or whether it supports a broader perspective where a multiplicity of stakeholders is afforded equal attention.

\section{The impact of professionalisation on the perception of the corporate environment}

\subsection{Expertise}

One feature of professions is an academic education in a field that provides exclusive knowledge. In traditional professions, this is a mandatory requirement for entry into the profession. In most countries, there is no such requirement for corporate communication. However, more and more universities are now offering degrees in public relations, corporate or business communication and are keen to receive some kind of accreditation (Fitch, 2014).

An overwhelming majority of the respondents $(86.7 \%)$ hold an academic degree. Social sciences and humanities $(38.7 \%)$ are slightly more represented than business and marketing studies (31.2\%). It is striking that $11.5 \%$ studied a subject that is not linked to corporate communication in any way, while only $5.4 \%$ specialised in public relations / communication management.

How does the degree of specialisation of the respondents' education relate to the prioritisation of the organizational environment at their subsequent workplace?
Table 4: Mean comparison of the prioritisation of environments (factor values) with regard to educational background

\begin{tabular}{lrrrr}
\hline & Politics & Media & Market & Investors \\
\hline $\begin{array}{l}\text { Academic degree with } \\
\text { a specialisation in }\end{array}$ & -.27 & .53 & .36 & .00 \\
CC / PR & & & & \\
$\begin{array}{l}\text { Academic degree in } \\
\text { humanities/social }\end{array}$ & .00 & .17 & -.09 & -.14 \\
$\begin{array}{l}\text { sciences without } \\
\text { specialisation in }\end{array}$ & & & & \\
CC / PR & & & & \\
$\begin{array}{l}\text { Academic degree in } \\
\text { marketing/business }\end{array}$ & -.03 & -.21 & .14 & .15 \\
$\begin{array}{l}\text { without specialisation } \\
\text { in CC / PR }\end{array}$ & & & & \\
$\begin{array}{l}\text { Other academic } \\
\text { degrees }\end{array}$ & .19 & .05 & .00 & .20 \\
No academic degree & .01 & -.09 & .02 & -.02 \\
Sign. (ANOVA) & .757 & .046 & .427 & .213 \\
\hline
\end{tabular}

Note: $\mathrm{N}=217$

Table 4 shows one significant difference when comparing the respective means of the factor values which indicate the salience of organizational environments: respondents who received specialized education in corporate communication tend to focus on the media at work.

There are similar tendencies when analysing the workload in corporate communications. The workload of doctors in hospitals is usually calendared by medical tasks. While they might complain about too many admin tasks, they are certainly not driving the ambulance and they are not involved in the bookkeeping. Things are different in the field of corporate communication. On average, more than one quarter of the workload of the respondents $(26.4 \%)$ consists of duties that are not di-

Table 5: Correlation between the prioritisation of environments (factor values) with the average amount of workload in CC/PR

\begin{tabular}{lrrrr}
\hline & Politics & Media & Market & Investors \\
\hline CC/PR Workload & .14 & .43 & -.19 & .00 \\
Sign. (Pearson's r) & .014 & .000 & .001 & .970 \\
\hline
\end{tabular}

Note: $\mathrm{N}=294$ 
rectly related to their expertise. This may indicate a lack of a distinct definition of the professional role within the corporation. However, table 5 shows what it is that supports the development of a clear-cut profile: again, it is media orientation. The less the heads of corporate communication are 'bothered' with out-of-profession duties, the more they focus on media as external stakeholders. Once again, it is the media orientation that shows a strong link with professional identity.

\subsection{Autonomy}

Indicators of autonomy can be located on the societal, the organizational and the individual level:

, Are practitioners organized in a professional association representing their interests vis-à-vis society?

, Is there a corporate communication department in the organization or is CC incorporated into other areas?

, How do the respondents perceive their individual impact on organizational decisions?

A majority of all heads of corporate communication are not organized in a professional communication association (57.1\%). The only significant results of the mean comparison with regard to the prioritisation of organizational environments is in line with the previous results (see table 6): Respondents who are a member of a professional association pay more attention to the media than to other context areas.

Table 6: Mean comparison of the prioritisation of environments (factor values) with regard to membership rates in professional associations

\begin{tabular}{lrrrr}
\hline & Politics & Media & Market & Investors \\
\hline $\begin{array}{l}\text { Member of a commu- } \\
\text { nication association }\end{array}$ & .09 & .18 & .09 & .10 \\
$\begin{array}{l}\text { Not a member of } \\
\text { a communication }\end{array}$ & -.01 & -.13 & -.01 & -.05 \\
association & & & & \\
Sign. (ANOVA) & .429 & .014 & .447 & .230 \\
\hline Note: $\mathrm{N}=260$. & & & &
\end{tabular}

Communication associations are handicapped if a majority of practitioners are not involved, making it more difficult to legitimise a prominent societal role for the profession. Nevertheless, the importance of CC on the meso level of organizations is highly rated, if we take the existence of a communication department as a structural indicator. Almost three quarters (74.3\%) of the most senior positions in corporate communications are head of a CC department. Our results show that such a strong position of communication within the organization can most likely be explained citing media salience. Respondents who run a CC department focus more on the media than on other environmental segments (see table 7). A perceived relevance of political stakeholders also goes hand in hand with a structural autonomy of CC, whereas a focus on market stakeholders often makes a CC department more expendable.

Table 7: Mean comparison of the prioritisation of environments (factor values) with regard to the existence of CC departments in the organization

\begin{tabular}{lrrrr}
\hline & Politics & Media & Market & Investors \\
\hline CC department exists & .07 & .16 & -.08 & -.05 \\
No CC department & -.25 & -.58 & .26 & .18 \\
Sign. (ANOVA) & .021 & .000 & .013 & .091 \\
\hline
\end{tabular}

Note. $\mathrm{N}=292$

On the level of individual professional autonomy, we asked respondents to rate the following statement on a seven-point Likert scale: "I have a significant impact on strategic decisions of the company." The average is 5.1 ; the respondents are fairly confident about their organizational power. Once again, this correlates with the media orientation, but this time the respondents feel even better positioned within their organization when they specifically target political stakeholders (see table 8). Respondents who deal with the political implications of organizational activities appear to be more powerful in their organization compared to corporate commu- 
Table 8: Correlation between the prioritisation of environments (factor values) and the perception of the individual impact on organizational decisions

\begin{tabular}{lrrrr}
\hline & Politics & Media & Market & Investors \\
\hline $\begin{array}{l}\text { Perceived individual } \\
\text { impact }\end{array}$ & .26 & .17 & .08 & .06 \\
Sign. (Spearman's r) & .000 & .004 & .163 & .315 \\
\hline
\end{tabular}

Note: The respondents rated the following statement on a seven-point Likert scale: "I have a significant impact on strategic decisions of the company." $\mathrm{N}=288$

nication roles that are less political. One might argue that the political power of a stakeholder transfers into an intra-organizational resource for the employees dealing with these stakeholders.

\subsection{Value orientation}

Finally, we examined value orientation. Professions need to present a strong ethical commitment in order to justify a superior role within their organization and in respect of society as a whole. Accordingly, public relations associations are keen to adopt ethics codes. A variety of values are included in these codes: we selected transparency, which is more unique to corporate communication than to other occupational fields.

In survey research, whenever respondents are asked about their commitment to values that seem to be widely accepted in society, socially desirable answers pose a problem. Therefore, we provided a seven-point-scale between two opposing statements, both of which are justifiable on normative grounds:

\footnotetext{
"We try to avoid publicity when dealing with stakeholders. Problems can be more easily solved without any publicity." (1)

"Transparency and an open discussion within the public sphere are very important for my organization. The wider public has a right to know what is going on." (7)
}

The average is 4.3 , only slightly above 4 , which is the middle point on the scale. This means that we probably obtained answers without much bias toward social desirability. Respondents with a strong media or political orientation show a comparably strong commitment to transparency (see table 9). The public and political spheres are seen as crucial platforms securing transparency as a core value of professional communicators (Vattimo, 1992). In contrast, corporate communication with a focus on the market or investors shows less commitment to societal claims.

Table 9: Correlation between the prioritisation of environments (factor values) and the commitment to transparency as a professional value

\begin{tabular}{lrrrr}
\hline & Politics & Media & Market & Investors \\
\hline Transparency & .24 & .27 & .06 & .00 \\
Sign. (Spearman's r) & .000 & .000 & .356 & .954 \\
\hline
\end{tabular}

Note: The respondents rated the following opposing statements on a seven-point scale: 1 = "We try to avoid publicity when dealing with stakeholders. Problems can be more easily solved without any publicity." 7 = "Transparency and an open discussion within the public sphere are very important for my organisation. The wider public has a right to know what is going on." $\mathrm{N}=267$

\section{Summary and discussion}

It's still the media! - The findings of this article challenge the widespread understanding of professionalisation in corporate communication as a development from media relations to an integrated communication management that accounts for the multiplicity of stakeholder claims and the diversity of corporate environments in complex modern societies. Instead, unique skills and claims when dealing with the media remain crucial for the identity of corporate communication practitioners. This is at the core of their professional profile, allowing them to draw a line between themselves and those involved in marketing, advertising and management in the organization. Thus, our results challenge the equation of professional communication with multi-stakeholder-management. Professionalism does not go hand in hand with a 360-degree view of corporate environments. Instead, it supports specialisation on a distinct stakeholder segment: the media. Consequently, the communication department might easily fail to be the cen- 
tral instance for an integrated strategy going beyond the media context.

Our data are derived from a cross-cultural survey of heads of corporate communication in the biggest companies in five countries: Australia, Austria, Indonesia, Germany and Switzerland. We operationalised three dimensions of professionalism: expertise, autonomy, value orientation. We measured the impact of these dimensions on four orientations in respect of the organizational environments: an orientation toward politics, the media, markets and investors. These four dimensions resulted from a factor analysis comprising the perceived relevance of 18 stakeholder groups and 13 communication areas. Ultimately, it is the focus on the media that shapes the professional identity of corporate communication practitioners around the world. Respondents ...

, who graduated in public relations or communication management (expertise).

, who are engaged primarily with communication tasks (expertise)

, who are members of a professional communication association (autonomy)

, who are the head of a communication department in their organization (autonomy)

, who perceive a high impact on organizational decisions (autonomy)

, who are committed to transparency as a professional value (value orientation)

... tend to focus on the media within their external environment. It is not the case that a higher degree of expertise, autonomy and value orientation supports a broad multi-stakeholder orientation of practitioners beyond the media.

From a broader organizational perspective, the results support the characterisation of corporate communication as a fragmentary and fluid process, which is influenced by many players within the organization instead of being monopolized by a few communication professionals. Thus, the results question the professional manageability of communication and its "ideals of wholeness, unity and integration" (Christensen \& Cornelissen, 2011, p. 406), which might contribute to unrealistic expectations (Fröhlich, 2013). Nevertheless, the equation of professional communication with a broad and integrated multi-stakeholder management might still work as a paradigm for managerial discourses. Its function is to legitimize the ambitions of practitioners who aim to boost their occupational status and societal acceptance (Evetts, 2008). This might hold especially true for public relations, which suffers from negative public images that could result in a lack of appreciation within the organization (Saltzman, 2012).

\section{$7 \quad$ Limitations and conclusions}

There are limitations to our study and we should proceed with caution when making generalisations based on these results. An appropriate interpretation of the identified strong media orientation of communication professionals demands an answer to the key question: What do the media stand for? Whom do they represent? There are at least three possible theoretical answers. First, the media are conceptualized as a distinct system in the business environment that constitutes societal realities according to its own logic (e.g. news value). If this is the answer, then the media orientation would be blind toward other constitutions of reality from other parts of society. Secondly, the media are seen as a channel or a platform allowing a diversity of stakeholders to raise their voice. If this is the answer, then the media orientation could indeed stand for a kind of 'mediatised' multi-stakeholder management. Thirdly, the media are assumed to be dependent on other societal forces. If they are highly commercialised, then media orientation might in fact indicate a market orientation. Media relations would primarily mean writing advertorials within a marketing department. If the media are dependent on political elites, then the media orientation could in fact indicate a political orientation. Media relations is then transformed into a tool of public affairs. 
Our survey spanned five countries with different media systems (e.g. rather politicised in Indonesia and rather commercialised in Australia). When performing the analysis on a country-by-country basis, some of the significant results are lost, which could be due to the reduced sample size. However, we did not find country-specific results indicating a direction contrary to the overall findings. Thus, we would reject the third option: Professionals treat media not so much as a representation of a dominant 'third party'; media are stakeholders in their own right, creating realities according to their own logic, or they are seen as a societal platform calling for a 'mediatised' multi-stakeholder management. Both options relate to different theoretical concepts of the media society (e.g. Luhmann, 2000; Habermas, 2006), but they are not mutually exclusive in empirical terms. The corporate specialist for the media might also be the generalist for society. Nevertheless, we must reject the familiar story of professionalisation as a linear development from media relations to integrated communications. Particularly against the backdrop of the rise of social media, new research questions need to be formulated. Thus, what is important is not necessarily 'media relations or multi-stakeholder management?' - we also need to ask how best to organize professional media relations in order to achieve a diversity of stakeholders.

Additionally, the impact of the cultural and institutional context as an intervening variable needs to be analysed in more detail (Ingenhoff \& Ruehl, 2013). This continues to be a limitation of the study, despite the fact that we used a cross-cultural database. Furthermore, sample sizes need to be increased to include smaller organizations and practitioners below the most senior level. This will allow for the testing and inclusion of more indicators for both professionalism and the perception of corporate environments. In consequence, a number of potentially-intervening variables could be added to multivariate models. This should be accompanied by qualitative indepth studies, which might identify new types of postmodern professionalism that leave the assumptions of sociological trait approaches behind. After all, this article argues for a critical reflection about our accepted 'textbook' understanding of professional corporate communication.

Finally, the practical implications need to be discussed. We do not propose that practitioners should abandon the normative idea of multi-stakeholder management. On the contrary: it could guide the way towards a new understanding of professionalism, a different kind of 'value orientation' which accounts for the diversity of corporate environments. However, such a role understanding cannot be based concurrently on traditional autonomy claims and the monopolization of expertise. This would be the wrong direction in times of uncertainty and multiple information sources where interconnected societies are experiencing a general trend towards de-professionalisation (Faber, 2002). The expertise of medical doctors or university scholars, for instance, is increasingly being called into question. This results in a loss of professional autonomy and the undermining of value orientations by bureaucratic pressures and market imperatives. It is the great misfortune of the communication industry and perhaps somewhat ironic that this sector is fervently seeking to push its own professionalisation project at precisely the time we are seeing a growing trend towards de-professionalisation across the board. However, this situation also represents a chance to reinvent the idea of professionalism beyond claims of autonomy, control, segregation and exclusive expertise (Serini, 1993; Hoffmann, Röttger, \& Jarren, 2007). Communication managers who strive for structural openness and focus on their boundary spanning function could indeed be the frontrunners for a new breed of professionalism. Ultimately, professional identities in the 21 st century will be formed by those who build bridges, not walls.

\section{Acknowledgements}

The article uses data from the project "CCCC - Comparing Corporate Commu- 
nication Cultures". The project has been set up by communication scholars from five countries: Jochen Hoffmann (Department of Culture and Global Studies, Aalborg University, Denmark; formerly Curtin University, Australia), Diana Ingenhoff (Department of Communication and Media Research, University of Fribourg, Switzerland), Anis Hamidati (Department of Communication and Public Relations, Swiss German University, Indonesia), Kurt Luger (Department of Communication Science, University of Salzburg, Austria), and Ulrike Röttger (Department of Communication, University of Münster, Germany).

\section{References}

Argentini, P. (2009). Corporate communication (5th ed.). New York: McGraw-Hill.

Bernstein, D. (1984). Company image and reality: A critique of corporate communications. Eastbourne, NY: Holt, Rinehart and Winston.

Cameron, G.T., Sallot, L. M., \& Weaver-Lariscy, R. A. (1996). Developing standards of professional performance in public relations. Public Relations Review, 22 (1), 43-61. doi: 10.1177/107769589805300202

Chhokar, J. S., Brodbeck, F. C., \& House, R. J. (Eds.). (2008). Culture and Leadership Across the World: The GLOBE Book of InDepth Studies of 25 Societies. New York: Taylor \& Francis.

Christensen, L. T. \& Cornelissen, J. (2011). Bridging corporate and organizational communication: review, development and a look to the future. Management Communication Quarterly, 25 (3), 383-414. doi: 10.1177/0893318910390194

Christensen, L. T., Morsing, M., \& Cheney, G. (2008). Corporate Communications. Convention, Complexity, and Critique. London: Sage.

Cornelissen J. (2014). Corporate Communication. A Guide to Theory and Practice $\left(^{\text {th }}\right.$ ed.). London: Sage.

De Bussy N. M. \& Wolf K. (2009). The state of Australian public relations: Professionalisation and paradox. Public Relations
Review, 35 (4), 376-381. doi: 10.1016/j. pubrev.2009.07.005

Elliott, P. \& Ross C. (1972). The sociology of the professions. London: Macmillan.

Evett, J. (2008). The management of professionalism: A contemporary paradox. In $\mathrm{Ge}$ wirtz, S., Mahony, P., Hextall, I., \& Cribb, A. (Eds.), Changing teacher professionalism. International trends, challenges, and ways forward (pp. 19-30.). London: Routledge.

Faber, B. (2002). Professional identities. What is professional about professional communication? Journal of Business and Technical Communication, 16 (3), 306-337. doi: $10.1177 / 105065190201600303$

Fitch, K. (2014). Professionalization and public relations education: Industry accreditation of Australian university courses in the early 1990s. Public Relations Review, 40 (4), 623-631. doi: 10.1016/j.pubrev.2014.02.015

Fombrun, C. J. \& Rindova, V. P. (2000). The road to transparency: reputation management at Royal Dutch/Shell. In Schultz M., Hatch, J., \& Larsen, M. H. (Eds.), The expressive organisation. Lining identity, reputation and the corporate brand (pp. 7798). Oxford, UK: Oxford University Press.

Freeman, R. E., Harrison, J. S., Wicks, A. C., Parmar, B. L., \& De Colle, S. (2010): Stakeholder Theory, The State of the Art. Cambridge: Cambridge University Press.

Freidson, E. (1970). Profession of medicine; $a$ study of the sociology of applied knowledge. New York: Dodd, Mead \& Company.

Freidson, E. (1994). Professionalism Reborn. Theory, Prophecy and Policy. Cambridge: Polity Press.

Fröhlich, R. (2013). Young future PR-professionals: Perceptions of the future occupational field and assessment of current PR education. A survey of tertiary level students in Austria, Germany and Switzerland. Studies in Communication Sciences, 13, 24-32. doi: 10.1016/j.scoms.2013.04.002

Gilpin, D. E. \& Murphy, P. (2010). Implications of complexity theory for public relations. In Heath, L. (Ed.): The Sage Handbook of Public Relations (2nd. Ed.), (pp. 71-83). Thousand Oaks; CA: Sage.

Gregory, A. (2011). The state of the public relations profession in the UK. A review of the first decade of the twenty-first century. 
Corporate Communications, 16 (2), 89-104. doi: 10.1108/13563281111141633

Grunig, L. A., Grunig, J. E., \& Dozier, D. M. (2002). Excellent public relations and effective organizations. A study of communication management in three countries. New York, NY: Routledge.

Gupta, S. (2007). Professionalism in Indian public relations and corporate communications: An empirical analysis. Public Relations Review, 33 (3), 306-312. doi: 10.1016/j.pubrev.2007.05.011

Habermas, J. (2006). Political communication in media society. Does democracy still enjoy an epistemic dimension? The impact of normative theory on normative research. Communication Theory, 16, 411-426. doi:1 0.1111/j.1468-2885.2006.00280

Hazleton, V. \& Sha, B. L. (2012). Generalizing from PRSA to public relations: How to accommodate sampling bias in public relations scholarship. Public Relations Review, 38 (3), 438-445. doi: 10.1016/j. pubrev.2011.04.005

Hoffmann, J., Röttger, U., \& Jarren, O. (2007). Structural segregation and openness: Balanced professionalism for public relations. Studies in Communication Sciences, 7 (1), 125-146.

Hoffmann, J. (2016). All roads lead down under? Ethnocentrism among Australian corporate communication practitioners. Communication Research and Practice, 2 (2), 244-262. doi: 10.1080/22041451.2016.1186486

Hoffmann, J., Hamidati, A. (2016). Beyond professional snail races: Contextualising corporate communication in Indonesia. Journal of Public Relations Research, 28 (1), 51-66. doi: 10.1080/1062726X.2015.1131698

Hoffmann, J., Röttger, U., Ingenhoff, D., \& Hamidati, A. (2015). The rehabilitation of the "nation variable". Links between corporate communications and the cultural context in five countries, Corporate Communications, 20 (4), 483-499. doi: 10.1108/CCIJ10-2014-0071

Holtzhausen, D. R., Petersen, B. K., \& Tindall, N. D. (2003). Exploding the myth of the symmetrical/asymmetrical dichotomy: Public Relations in the New South Africa.
Journal of Public Relations Research, 15 (4), 305-341. doi: 10.1207/S1532754XJPRR1504_02

House, R. J., Hanges, P. J., Javidan, M., Dorfman, P. W., \& Gupta, V. (2004). Culture, Leadership, and Organizations: The GLOBE Study of 62 Societies. London: Sage.

Huang, Y. H. (2012). Gauging an integrated model of public relations value assessment (PRVA): scale development and cross-cultural studies. Journal of Public Relations Research, 24 (3), 243-265. doi:10.1080/1062 726X.2012.671987

Ingenhoff, D. \& Ruehl, C. (2013). International public relations: A synopsis of German-speaking and Anglo-American research approaches. Studies in Communication Sciences, 13, 3-14. doi: 10.1016/j. scoms.2013.04.007

Kim, S. Y. \& Reber, B. H. (2009). How public relations professionalism influences corporate social responsibility: A survey of practitioners. Journalism and Mass Communication Quarterly, 86 (1), 157-174. doi: $10.1177 / 107769900908600110$

Kim, Y. \& Hon, L. C. (1998). Craft and professional models of public relations and their relation to job satisfaction among Korean public relations practitioners. Journal of Public Relations Research, 10 (3), 155-175. doi: 10.1207/s1532754xjprr1003_01

Kirat, M (2006). Public relations in the United Arab Emirates: The emergence of a profession. Public Relations Review, 32 (3), 254-260. doi: 10.1016/j.pubrev.2006.05.006

Larson, M. S. (1977). The rise of professionalism: A sociological analysis. Berkeley: University of California Press.

Li, C., Cropp, F., Sims, W., \& Jin, Y. (2012). Perceived professional standards and roles of public relations in China: Through the lens of Chinese public relations practitioners. Public Relations Review, 38 (5), 704-710. doi:10.1016/j.pubrev.2012.05.001

Lim, S, Goh, J., \& Sriramesh, K. (2005). Applicability of generic principles of excellent public relations in a different cultural context: The case study of Singapore. Journal of Public Relations Research, 17 (4), 315340. DOI: 10.1207/s1532754xjprr1704_1 
Luhmann, N. (2000). The reality of the mass media. Stanford, CA: Stanford University Press.

Mellado, C. \& Barria, S. (2012). Development of professional roles in the practice of public relations in Chile. Public Relations Review. 38 (3), 446-453. doi: 10.1016/j. pubrev.2012.04.001

Niemann-Struweg, I. \& Meintjes, C. (2008). The professionalism debate in South African public relations. Public Relations Review, 34 (3), 224-229. doi: 10.1016/j. pubrev.2008.03.029

Pal, M. \& Dutta, M. J. (2008). Public relations in a global context: The relevance of critical modernism as a theoretical lens. Journal of Public Relations Research, 20 (2), 159-179. doi: 10.1080/10627260801894280

Parsons, T. (1968). Professions. In Sills D. (Ed.), International Encyclopedia of the Social Science, 12, 536-547.

Pieczka, M. (2000). Objectives and Evaluation in Public Relations Work: What do they tell us about Expertise and Professionalism? Journal of Public Relations Research, 12 (3), 211-233. doi: 10.1207/S1532754XJPRR1203_1

Pieczka, M. \& L'Etang, J. (2000). Public Relations and the Question of Professionalism. In Heath, R. L. (Ed.), Handbook of Public Relations, Thousand Oaks: 223-235.

Röttger, U., Hoffmann, J., \& Jarren, O. (2003). Public Relations in der Schweiz, Eine empirische Studie zum Berufsfeld Öffentlichkeitsarbeit, Konstanz: UVK.

Saltzman, J. (2012). The Image of the Public Relations Practitioner in Movies and Television, 1901-2011. The IJPC Journal, 3, 1-50.

Serini, S. A. (1993). Influences on the Power of Public Relations Professionals in Organizations: A Case Study. Journal of Public Relations Research, 5 (1), 1-25. doi: 10.1207/ s1532754xjprr0501_01

Slabbert, Y. \& Barker, R. (2014). Towards a new model to describe the organisation-stakeholder relationship-building process: A strategic corporate communication perspective. Communication 40 (1), 69-97 doi: $10.1080 / 02500167.2014 .875481$

Sriramesh, K. \& Verčič, D. (Eds.) (2009). The global public relations handbook: Theory, research and practice (2nd Ed.) (pp. 3-21). Mahwah, NJ: Lawrence Erlbaum.

Vattimo, G. (1992). The transparent society. Cambridge: Polity.

Wright, D. K. (1979). Professionalism and social responsibility in public relations. Public Relations Review, 5 (3), 20-33. doi: 10.1016/S0363-8111(79)80025-9

Wu, M. Y. \& Taylor, M. (2003). Public relations in Taiwan: Roles, professionalism and relationship to marketing. Public Relations Review, 29 (4), 473-483. doi: 10.1016/j. pubrev.2003.08.008

Wylie, F. W. (1994). Commentary: Public relations is not yet a profession. $\mathrm{Pub}$ lic Relations Review, 20 (1), 1-3. doi: 10.1016/0363-8111(94)90109-0

Zulhamri, A. \& Threadgold, T. (2008). Towards the professionalization of public relations in Malaysia: Perception management and strategy development. Public Relations Review, 34 (3), 285-287. doi: 10.1016/j. pubrev.2008.04.003 